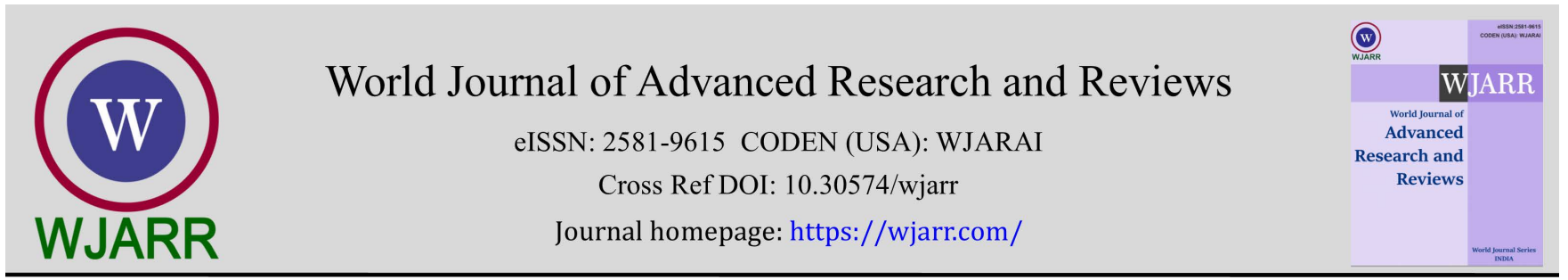

(RESEARCH ARTicle)

Check for updates

\title{
Morphometric characterization of Rastrococcus invadens on four varieties of mango trees (Pout, Thies)
}

\author{
Amadou Fall 1, ${ }^{*}$, Adiouma G.R. J. Sarr ${ }^{2}$, Fawrou Seye ${ }^{3}$, Mamour Toure ${ }^{4}$, Raymond D. Ndione ${ }^{1}$ and Mady \\ Ndiaye 1 \\ ${ }^{1}$ Cheik Anta DIOP University, Faculty of Sciences and Technology, Department of animal Biology, Biology Reproduction \\ Laboratory, Senegal. \\ ${ }^{2}$ Cheik Anta DIOP University, Faculty of Sciences and Technology, Department of animal Biology, Entomolology and \\ Acararology Laboratory, Senegal. \\ ${ }^{3}$ Gaston Berger University, Department of Health Sciences, Senegal. \\ ${ }^{4}$ Gaston Berger University, UFR of Health Sciences, Senegal.
}

World Journal of Advanced Research and Reviews, 2021, 09(03), 116-124

Publication history: Received on 26 January 2021; revised on 01 March 2021; accepted on 04 March 2021

Article DOI: https://doi.org/10.30574/wjarr.2021.9.3.0072

\begin{abstract}
Rastrococcus invadens (Homoptera, Pseudococcidae) or mealybug is an insect pest of mango and several other fruit trees including citrus. The cochineal is native to Southeast Asia and was first identified in Senegal in Dakar in 1995. Since then, it has been widely distributed throughout the country and more particularly in the two most fruit-producing areas: Casamance and Thies. To properly conduct our study, we chose the four most infested mango varieties namely Kent, Keitt, Sewe and Boukodiekhal. All these populations are from the locality of Pout (Thies region). On each plant we collected 10 people. This allowed us to have a total of 40 individuals. The individuals harvested are coded according to the zone and the type of plant in which they were harvested.
\end{abstract}

This study revealed almost two more or less distinct morphometric groups made up on the one hand by populations from improved varieties (Kent and Keitt) and on the other by those from local varieties (Sewe and Boukodiekhal).

Keywords: Rastrococcus invadens; Mango tree varieties; Morphometric characterization; Niayes area

\section{Introduction}

The mango tree (Mangifera indica) is a flowering and fruiting plant (spermaphyte). It belongs to the Dicotyledonous class, the Sapindales order and the Anacardiaceae family. It is native to northern India at the foot of the Himalayan range [1].

It is a tree with a large, rounded, dense, spreading crown that can reach $30 \mathrm{~m}$ in height with a well-individualized monopod trunk [2]. It has a pivoting root system with some ramifications for a good anchoring to the ground well adapted to the search for water table under conditions of water stress [3]. In Senegal, the mango has been identified as one of the horticultural sector value chains with interesting potential on the American, European and sub-regional markets [4]. Indeed there are several varieties among which one can quote: kent, keitt, sewe, boukodiekhal, mango papaya. Studies have shown that the first four varieties are the most attacked by $R$. invadens [5]. The objective of this

\footnotetext{
*Corresponding author: Amadou Fall

Cheik Anta DIOP University, Faculty of Sciences and Technology, Department of animal Biology, Biology Reproduction Laboratory, Senegal.
}

Copyright (c) 2021 Author(s) retain the copyright of this article. This article is published under the terms of the Creative Commons Attribution Liscense 4.0. 
work is to take stock of the morphological and morphometric characters of the pest of fruit plants in a single area. agro ecological on the four varieties of mango trees most attacked.

\section{Material and methods}

\subsection{Presentation of mango varieties}

In Senegal, the mango has been identified as one of the value chains of the horticultural sector with interesting potential on the American, European and sub-regional markets [4]. Indeed there are several varieties among which one can quote: kent, keitt, sewe, boukodiekhal, mango papaya. Our study focuses on four varieties most attacked by $R$. invadens, namely: The Kent variety, which represents more than $70 \%$ of exported mangoes, produces a large fruit with a purplishred exterior color with a tender and juicy orange flesh, without fiber. Its taste quality is excellent. It resists well to maritime transport; The Keitt variety is the second variety exported by the countries of the sub-region. Later, of a pinkish-red color, it has a firm yellow flesh, without fibers, but its skin is thin and fragile, sensitive to handling. However, its slow maturation process makes it suitable for maritime transport. The Boukodiekhal variety is a local variety generally not appreciated for export. It has a green color, becoming slightly orange, with orange flesh, and presents fibers with very good taste quality; The Sewe variety is also a local variety. It presents fruits of very small size and yellow in color when ripe with a sweet taste but very rich in fiber and not exported to the international market.

\subsection{Presentation of the insect}

Rastrococcus invadens is an insect native to Southeast Asia (Figures 1). It belongs to the phylum Arthropods, to the class of Insects, to the order of Orthoptera, to the superfamily Coccoidea and to the family of Pseudococcidae.

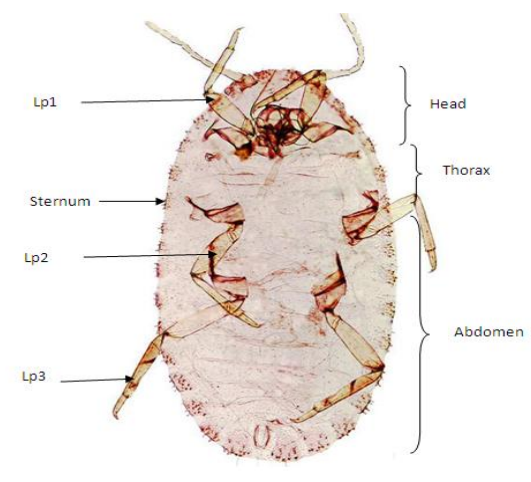

Figure 1 Rastrococcus invadens (5)

\subsection{Sampling}

The work took place between May and June 2020 on a farm located in the town of Pout.

Four populations of R. invadens [6] were compared in this study: a population originating from the Kent variety, one from Keitt, one from Sewe and another from Boukodiekhal. All these populations are from the locality of Pout (region of Thies).

Table 1 Summary table of sampling.

\begin{tabular}{|c|c|c|c|c|}
\hline Codes & Plant species & Localities & Number of individuals & Regions \\
\hline TPVk & Kent & Pout & 10 & Thies \\
\hline TPVki & Keit & Pout & 10 & Thies \\
\hline TPVs & Séwé & Pout & 10 & Thies \\
\hline TPVkb & Boukodiekhal & Pout & 10 & Thies \\
\hline
\end{tabular}

TPVk:Thiés-PoutVarietékent ;TPVki :Thiés-Pout Varietékeit ; TPVs:Thiés-PoutVarietéSéwé ;TPVb:Thiés-PoutVarietéboukodiékhal.

On each plant we collected 10 individuals. This allowed us to have a total of 40 individuals. The individuals harvested are coded according to the zone and the type of plant in which they were harvested. The data are grouped together in 
Table 1 below. In general, morphometric analysis of $R$. invadens larvae is destructive. Indeed, it requires the prior death of individuals and their fixation in alcohol [7].

\subsection{Morphometric study}

We have chosen 10 measurable variables with a reasonable degree of precision. These are essentially the length of the insect's body, body width, head length and head width, length of the hind legs, middle legs and front legs. Add to this the length of the abdomen, length of the thorax and the average diameter of the sternum (Table 2). The parts concerned were mounted on a binocular magnifying glass incorporated with a camera connected to a computer. The observations were carried out on individuals of the L3 (3rd larval stage) which corresponds in the male to the pre-pupa. The harvested specimens are then cleaned in 70 alcohol before taking the measurements and each piece being carefully separated from neighboring pieces. Each individual in a sample is paired with a code, using the first letter of the region in uppercase followed by the first letter of the locality of origin and finally the first letter of the plant species considered, (Table 2).

Table 2 Choice of values

\begin{tabular}{|c|c|c|c|}
\hline Body & Head & Thorax & Abdomen \\
\hline LC: body length & LT: head length & LT: thorax length & La: length of abdomen \\
\hline lc: body width & lt: head width & $\begin{array}{c}\text { Lp1: length of the first } \\
\text { pair of legs }\end{array}$ & $\begin{array}{c}\text { Ls1: length of the first } \\
\text { sternum }\end{array}$ \\
\hline & & $\begin{array}{c}\text { Lp2: length of the } \\
\text { second pair of legs }\end{array}$ & \\
\hline & & $\begin{array}{c}\text { Lp3: length of the } \\
\text { third pair of legs }\end{array}$ & \\
\hline
\end{tabular}

\subsection{Statistical analyzes}

\subsubsection{Gross measurements}

After the choice of the number of axes to be retained, according to the elbow criterion (which makes it possible to obtain the best factorial plan), a principal component analysis (PCA) of the populations with the raw measurements of the variables with the R software version 3.2 .3 from [8]. The purpose of the PCA is to output the contribution of the variables on each factorial axis, to visualize the correlations between the variables.

\subsubsection{Transformed measurements}

Size effect and data transformation

The size effect results in a correlation circle that groups all the variables into a single plane for a given axis. This is an unwelcome effect, one that metric studies seek to overcome [9].The principle is therefore to eliminate this effect and reduce all individuals to the same size, in order to observe only differences in shape on the PCA. The elimination of the size effect in this study was performed according to the approach proposed by [10]; [9]; [11]; [12]; [13]

- Data log-transformation: our initial data table is made up of the variables $\mathrm{X} 1, \mathrm{X} 2, \ldots, \mathrm{Xp}$, we subsequently created a new data table made up of the variables $\log (\mathrm{X} 1), \log (\mathrm{X} 2), \ldots, \log (\mathrm{Xp})$;

- For each individual, we calculated the average over all the log-transformed variables. We consider this average score to be a good idea of the "size" for this individual;

- Finally, for each individual, we subtracted from each of these raw measurements the average height obtained with the log-transforms.

The size effect is thus eliminated and only the difference in shape will be observed on the PCA. The reduction in the weight of the factor (Size) leads to a reduction in the overall discrimination. This transformation was carried out in Excel version 2013. 


\subsubsection{Discriminant factor analyzes (DFA)}

A discriminant factor analysis (DFA) of the populations with the transformed data of the variables is carried out with $\mathrm{R}$ software version 3.2.3. It is performed with variables whose contribution is greater than or equal to $(1 / \mathrm{P}) \times 100$. It aims to see the best factor for grouping individuals according to their morphology.

\subsubsection{Determination of variables discriminating populations}

To determine the variables that significantly differentiate the morphology of populations, a Shapiro-Wilk test of normality of the data is first performed on each transformed log variable. When the p-value of the test is less than 0.05 , the corresponding log-transformed data does not follow the normal distribution and the Kruskal-Wallis test (nonparametric) is performed for a multiple comparison of the mean ranks of the populations of the corresponding variable. The Wilcoxon test (nonparametric) with the Bonferroni adjustment is performed to test the significance of the deviations in the mean ranks of the log-variables transformed by pair of populations. When the p-value is greater than 0.05, the log-transformed data follows a normal distribution and the Anova test is performed for a comparison of the mean of the transformed log variable.

\section{Results}

\subsection{Gross measurements}

\subsubsection{Choice of the number of axes to be used}

To obtain the number of axes to retain, we used the elbow criterion. The purpose of this criterion is to obtain the maximum conserved inertia with the minimum of factors. In our study two axes are retained, because the cut (the elbow) takes place at $\mathrm{K}=2$.

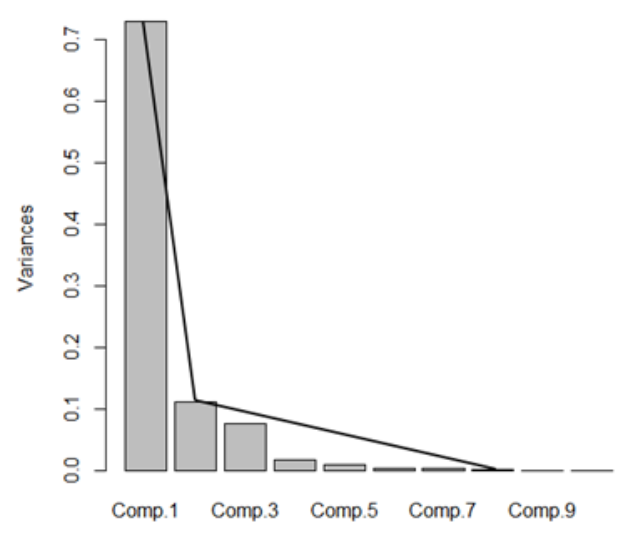

Figure 2 Choice of the number of factors

\subsection{Principal component analysis}

The principal component analysis of individuals from different varieties of mango trees reveals that the first two factor axes (dimension) best explain the morphometric variability with $87.3 \%$ of the inertial power. Along the factorial axis 1 (dimension 1) variables such as LT (F1 = 11.9), lt (F1 = 11.7), Lp1 (F1 = 11.6), Lp2 (F1 = 11.3), lc (F1 = 10.9), Lp3 (F1 = 10.1), largely participate in the construction of the first factorial axis with $74.26 \%$ of the power of inertia. On the other hand, variables such as Lc (F1 = 9.9) La (F1 = 9.2), Ls1 (F1 = 8.7), and Th $(F 1=4.38)$ contribute little to the construction of the first axis. The factorial axis 2 (dimension 2), with a low power of inertia (13.04\%) is largely constructed by the variables Th $(\mathrm{F} 2=44.6)$, Ls1 (F2 = 21.17), LC (F2 = 11.21), lt (F2 = 10.51) and Lc (F2 = 11.9). The other variables such as Lp3 (F2 = 4.27), Lp2 (F2 = 3.009), Lp1 (F2 = 2.16), La (F2 = 1.18) lt (F2 = 0.94), LT (F2=0.82) contribute little to the construction of this axis. On the first factorial axis, all the variables are positively correlated except for the length of the thorax (Th). Obviously, the size effect affects our PCA (principal component analysis) (Figure 3). An overall positive correlation for the variables, along the factorial axis of dimension 1, seems to suggest an influence of the data by the "size effect". 


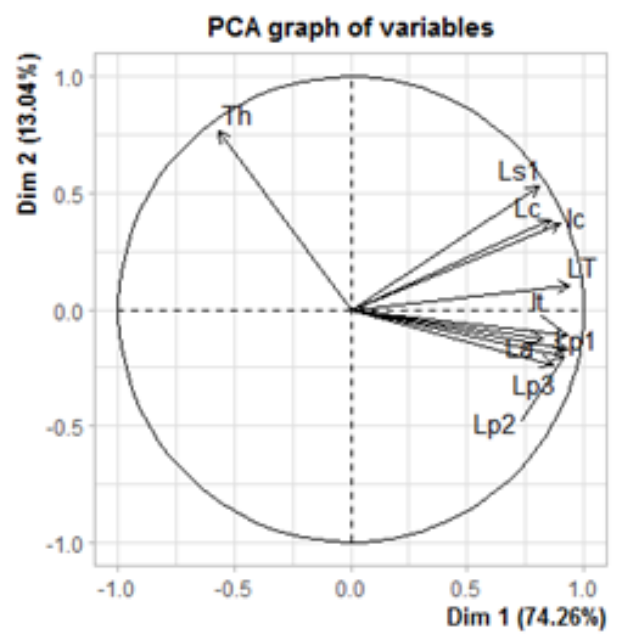

Figure 3 Correlation of the variables according to their contribution to the construction of the two dimensions (Dim. 1 and Dim. 2) with the raw data of the populations

\subsection{Transformed measurements}

\subsubsection{Choice of the number of axes to be retained after data transformation}

After transformation of the data, with the elbow criterion, two factorial axes are retained because $\mathrm{K}=2$.

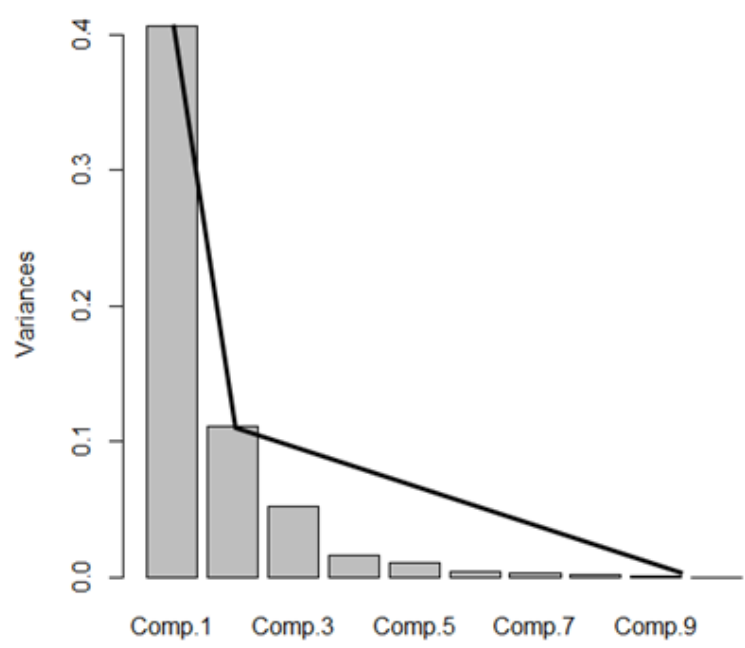

Figure 4 Choice of the number of factors after transformation

\subsection{Principal component analysis of transformed variables}

In comparison with the raw data, the principal component analysis of the transformed data shows a reduction in the percentage of inertia of $17.43 \%$ for the first dimension (factorial axis 1) following a decrease in the discriminating power of most of the variables at namely Lp3 $(\mathrm{F} 1=9.03)$, lc $(\mathrm{F} 1=8.35)$ and Lc $(\mathrm{F} 1=7.76)$. The second factorial axis with a very noticeable decrease (6.22\%), shows an almost identical situation, compared to the results with the raw data, with an increase in the discriminating power of almost all the variables and a significant contribution of certain variables such as LC $(\mathrm{F} 2=24.18)$, lc $(\mathrm{F} 2=18.61), \mathrm{Lp} 3(\mathrm{~F} 2=15.01)$, Ls1 $(\mathrm{F} 2=12.41), \mathrm{Lp} 2(\mathrm{~F} 2=10.64)$. The other variables such as Lp1 $(\mathrm{F} 2=6.04), \mathrm{La}(\mathrm{F} 2=5.15), \mathrm{Lt}(\mathrm{F} 2=4.36), \mathrm{Th}(\mathrm{F} 2=2.37)$ and lt $(\mathrm{F} 2=1.14)$. Better representation quality is always obtained with the plane formed by axes 1 and 2 with a total inertia percentage of $76.09 \%$. 


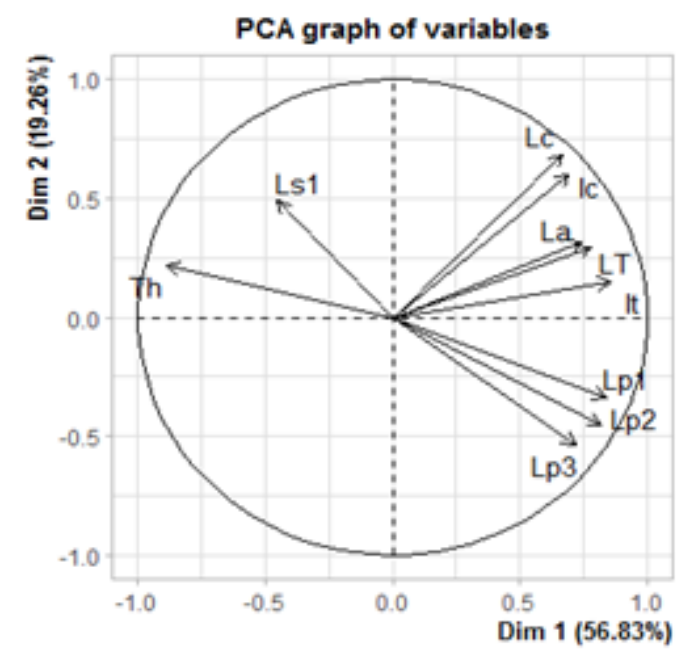

Figure 5 Correlation of the variables according to their contribution to the construction of the two dimensions (Dim. 1 and Dim. 2) with the transformed data of the populations

\subsection{Discrimination after transformation}

The best quality of representation of discriminant factor analysis (DFA) is obtained by the plane formed by the first two factor axes (Dim1 and Dim2) with 78.1\% of the percentage of inertia. The AFD of populations is carried out with variables whose contribution is greater than or equal to (1/P) $\times 100$ (the principal components).These variables are LC, lc, LT, lt, Th, Lp1, Lp2, Lp3 and Ls1. Following the first factorial axis (Dim1), with an inertia percentage of 57.6\%, the population of Sewe is distinguished from that of Kent and Boulkodiekhal. Following the second factorial axis (Dim 2), with an inertia percentage of $20.5 \%$, the population of Keitt is distinguished from those of Boukodiekhal and Kent.

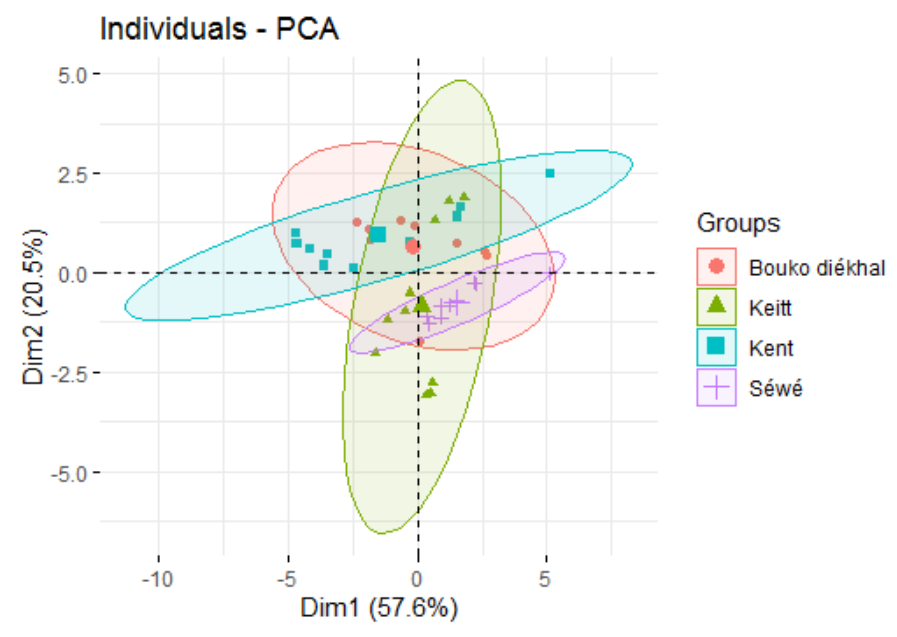

Figure 6 Representation in the main AFD plan of the populations of $R$. invadens after transformation of the variables

\subsection{Variables allowing discrimination after transformation}

According to the significance test, among the 10 variables studied, except the length of the body (LC), the length of the head (LT), the length of the abdomen (La) and the width of the head (lt) all the other variables make it possible to differentiate the populations of Kent and Keitt on the one hand and those of Sewe and Boukodiekhal on the other. Between these four populations, the variables like body width (lc), length of the abdomen (La), length of the thorax (Th), length of the first pair of legs (Lp1), length of the intermediate legs (Lp2) , length of the third pair of legs (Lp3), and length of the first sternum (Ls1) allow them to be distinguished. 
Table 3 Significance test of the means of the transformed log-variables.

\begin{tabular}{|c|c|c|c|c|c|}
\hline Variables & Boukodiekhal & Keitt & Kent & Sewe & $\begin{array}{l}\text { p-value de } \\
\text { Shapiro }\end{array}$ \\
\hline $\mathrm{LC}$ & $3.16 \pm 0.14^{\mathrm{a}}$ & $2.73 \pm 0.47 \mathrm{a}$ & $2.86 \pm 0.49 a$ & $2.86 \pm 0.36^{\mathrm{a}}$ & NS \\
\hline lc & $1.72 \pm 0.10^{\mathrm{a}}$ & $1.63 \pm 0.34^{\mathrm{a}}$ & $1.66 \pm 0.37^{a}$ & $1.66 \pm 0.18^{a}$ & $* *$ \\
\hline $\mathrm{LT}$ & $0.69 \pm 0.14^{a}$ & $0.69 \pm 0.15^{\mathrm{a}}$ & $0.71 \pm 0.18^{a}$ & $0.80 \pm 0.07 \mathrm{a}$ & NS \\
\hline lt & $1.06 \pm 0.13^{\mathrm{ab}}$ & $0.91 \pm 0.09 a$ & $0.90 \pm 0.23^{a}$ & $1.14 \pm 0.08^{b}$ & NS \\
\hline $\mathrm{La}$ & $1.88 \pm 0.33^{\mathrm{a}}$ & $1.65 \pm 0.15^{\mathrm{a}}$ & $1.69 \pm 0.25^{\mathrm{a}}$ & $1.69 \pm 0.18^{a}$ & NS \\
\hline $\mathrm{Th}$ & $0.56 \pm 0.24^{\mathrm{ab}}$ & $0.64 \pm 0.14^{\mathrm{ab}}$ & $0.67 \pm 0.17 \mathrm{a}$ & $0.82 \pm 0.06^{\mathbf{b}}$ & $* *$ \\
\hline Lp1 & $0.69 \pm 0.12^{\mathrm{a}}$ & $0.78 \pm 0.13^{a}$ & $0.67 \pm 0.17 \mathrm{a}$ & $0.82 \pm 0.06$ & $* *$ \\
\hline Lp2 & $0.72 \pm 0.14^{\mathrm{a}}$ & $0.88 \pm 0.07 \mathbf{a}$ & $0.74 \pm 0.17 \mathrm{a}$ & $0.91 \pm 0.09 a$ & $* *$ \\
\hline Lp3 & $0.76 \pm 0.16^{\mathrm{a}}$ & $0.96 \pm 0.08^{b}$ & $0.80 \pm 0.17^{\mathrm{ab}}$ & $0.96 \pm 0.08^{a}$ & $* *$ \\
\hline Ls1 & $0.35 \pm 0.02^{\mathrm{ac}}$ & $0.36 \pm 0.04^{a}$ & $0.45 \pm 0.06^{b}$ & $0.31 \pm 0.03^{c}$ & $* *$ \\
\hline
\end{tabular}

\section{Discussion}

Morphometric measurements of $R$. invadens show various values. In fact, for most variables, the measurements vary more or less according to a certain average. However, variables such as thorax length (Th) and first sternum length (Ls1) show constant values in all individuals sampled. These two variables therefore do not make it possible to discriminate between individuals from different populations. Thus, of the 10 variables chosen, only 8 variables (Lc, lc, Lt, lt, La, Lp1, Lp2 and Lp3) are used in order to obtain relevant information on the morphometric variability of the species. The first two factor axes explain $57.6 \%$ of the morphometric variability. According to the first factorial axis, the population of Sewe is distinguished from that of Kent and Boukodiekhal. Following the second factorial axis (Dim 2), with an inertia percentage of $20.5 \%$, the Keitt population is distinguished from those of Boukodiekhal and Kent. Indeed, the populations of these different varieties do not seem to present first seen great dissimilarities, due to the proximity of their point clouds; which could suggest an important gene flow between the different populations. However, an apparent correlation of most of the variables is due in large part to a common factor which can be assimilated at first approximation to a size factor. The decrease in the weight of this factor results in a slight decrease in the overall discrimination between the four varieties of mango trees. Thus, the transformed data leads to a reduction in the percentage of inertia of $17.43 \%$, for the first dimension (factorial axis 1 ) and $6.22 \%$ for the second factorial axis. This offers a better redistribution of the variables in relation to their contribution to the axis. With the transformed data, along the factorial axis 1, the first dimension allows discrimination of certain populations of Kent and Keitt and most of the populations of Sewe and Boukodiekhal. On the other hand, the second dimension reveals discrimination on the one hand between the Kent and Keitt populations and those of Sewe and Boukodiekhal. Insects from improved varieties (Kent and Keitt) are therefore distinguished from those from local varieties (Sewe and Boukodiekhal).

The organoleptic taste seems to correspond to a discriminatory criterion, therefore it is involved in the variation of the morphology of the species as well as the climatic conditions [14]. This could lead us to consider the mango tree as being the plant most affected. According to [15] the mango mealybug was first identified in Senegal in 1995 on the mango tree. The difference in the size of the insects would be linked to the varieties which each present a specific taste. This confirms the work of [16] which states that the development performance of insects is strongly influenced by nutritional quality.

\section{Conclusion}

The mealybug is a major constraint on the production of edible fruits in Senegal. This pest, the spread of which is favored by human activity (transport of plant material), very quickly reached a large part of Senegalese territory.

However, the study of the morphometric characterization of the populations of Rastrococcus invadens between the different varieties of mango tree made it possible to verify whether the distribution of the insect according to the plant 
species has an impact on its morphology. It revealed almost two more or less distinct morphometric groups made up on the one hand by populations from improved varieties (Kent and Keitt) and on the other by those from local varieties (Sewe and Boukodiekhal). But only more studies are needed in order to understand what is behind the existence of these less distinct groups.

\section{Compliance with ethical standards}

\section{Acknowledgments}

I begin by thanking everyone who has helped me in one way or another, or encouraged me during this work. The first lines of my thanks are dedicated to my director, Professor Mady NDIAYE, whom I cannot thank enough for accepting me in his laboratory. In addition to his human qualities, I remember the quality of the supervision, the unparalleled availability, the scientific vigilance, as well as his patience in correcting my writings. I also thank him for having broadened the fields of my skills, and for giving me free rein to participate in the training and educational activities of the license1 as a temporary employee. I would particularly like to thank my collaborators Dr Mamour TOURE, Dr Fawrou SEYE Dr Adiouma SARR, Dr Raymond Demba NDIONE for the availability, dynamism, kindness and above all the trust they have placed in me to establish this work. I would also like to thank all the research staff and doctoral students at UCAD who have provided me with help.

\section{Disclosure of conflict of interest}

No declaration of conflict of interest was noted.

\section{References}

[1] Arbonnier M.Arbres, Arbustes et Lianes des Zones Sèches d'Afrique de l'Ouest (2ème Ed), CIRAD-MNHN, Paris. $2002 ; 573$.

[2] Arbonnier M. Arbres, arbustes et lianes des zones sèches d'Afrique de l'ouest. CIRAD: Paris. $2000 ; 541$.

[3] FAO. Cahier de production et protection intégrées appliquée à la culture du manguier en Afrique soudanosahélienne, Projet G.C.P./RAF/244/BEL. 1999; 70.

[4] MCSI. Ministry of Commerce,. "Informal Sector of Consumption, promotion of local products and SMES 2016. The Mango Week of Senegal around the theme: The mango! Delicious treasure of West Africa May 31 to June 3, Dakar, Senegal. 2016.

[5] FALL A, TOURE M, SEYE F, NDIONE RD, BADIANE TS,NDIAYE M. Evaluation damage caused by Rastrococcus invadens (Willams. 1986) (Homoptera. Pseudococcidae) on mango in Casamance (Senegal) ISSN (e): 2413-3256, ISSN (p). 2413-8878. 2017; 3 (12): 114-119.

[6] DJ WILLIAMS. Rastrococcus invadens sp.n. (Homoptera: Pseudococcidae) introduced from the oriental region to West Africa and causing damage to mango, citrus and other trees. Bull. of Entomol. Research. 1986; 76: 695 699.

[7] Osafune K, Takasato M, Kispert A, Asashima M, Nishinakamura R. Identification of multipotent progenitors in the embryonic mouse kidney by a novel colony-forming assay. 2005; 151-61.

[8] R Core Team. A Language and Environment for Statistical Computing. R Foundation for Statistical Computing, Vienna, Austria. R Foundation for Statistical Computing, Vienna.2014.

[9] Santos F. Analyse en Composantes Principales (ACP): Travaux Pratiques avec le logiciel R. CNRS, UMR 5199 PACEA. 2015.

[10] DarrochJn, Mosimann I. Canonical and principal components of shape. Biometrika. 1985; 72(2): $241-252$.

[11] Dia AKM, Sarr AGRJ, Kafom A, Ngom D, Thiaw C, Ndiaye S, Sembène M. Identification morphométrique des populations de Tribolium castaneum Herbst (Coleoptera, Tenebrionidae inféodées à trios céréales à WidouThiengoli. Journal of Applied Biosciences. 2017; 119: 11929-11942.

[12] Sarr AGRJ, Dia CAKM, Ndiaye MR, Ngom D, Thiaw C, Ndiaye S,Sembène M. Morphometric characterization of Sitophilus zeamais Motschulsky (Coleoptera : Curculionidae) infesting differents maize varieties in west and central Africa. International Journal of Advanced Research (IJAR). 2017; 5(8): 1821-1835. 
[13] Dia AKM, Sarr AGRJ, Kafom A, Ngom D, Thiaw C, Ndiaye S, Sembène M. Morphological identification of trophic Tribolium castaneum populations Herbst (Coleptera, Tenebrionidae) in West Africa., Int. J. Adv. Res. 2018; 6(1): 203-216.

[14] FALLA, TOURE M, SEYE F, NDIONE RD, BADIANE TS, NDIAYE M. Morphometric characterization of the mango tree's mealy cochineal: Rastrococcus invadens on citrus tree in Senegal. International Journal of Agriculture, Environment and Bioresearch. 2019; 4(03): ISSN: 2456-8643.

[15] Han SH, Ndiaye AB, Hemptinne JL. Plantes-hôtes et prédateurs de la Cochenille farineuse du Manguier Rastrococcus invadens Williams, 1986, nouvellement introduite à Dakar, Sénégal (Hemiptera, Pseudococcidae). Bulletin de la Société entomologique de France. 2007; 112(1):121-125.

[16] Ming QL, Cheng C. Influence of nutrition on male development and reproduction in Tribolium castaneum J Econ Entomol. 2012; 105: 1471-1476. 